\title{
Expanding the Shelf Life of Tomato Fruits (Solanum Lycopersicum Mill) Using N-Hexan Extract of Date Seeds as Antifungal Agent
}

\section{Ismael $\mathrm{LQ}^{1}$, Al-Bader $\mathrm{SM}^{2 *}$ and Khoshnaw $\mathrm{AAO}^{3}$ \\ department of Medical Laboratory Science, Knowledge University, Iraq}

*Corresponding author: Salah M Al Bader, Department of Fungi, Knowledge University, Iraq,

Email: salahalbader@yahoo.com

\section{Research Article \\ Volume 3 Issue 1}

Received Date: October 18, 2019

Published Date: February 03, 2020

DOI: $10.23880 /$ oajmms-16000116

\section{Abstract}

Tomato fruits are a global commercialised vegetable which are consider as one of the faster perishable fruits. Microbial spoilage cause an important loss from the yield at pre and post harvesting periods.. To reduce fruits harm, a several postharvest application techniques are use, and the environmentally friendly aspects of these methods attract attention. This study was conducted to test the antifungal activity of $n$-hexan extract of date seeds against fungi which associated with tomatoes and cause spoilage.

Samples of tomatoes (local cultiver) were collected from markets in Erbil city during December 2018. Fruites were kept seperately for seven days in plastic cups with lids at lab environment. Seven fungal genera were isolated and identifiedAbsidia corymbifera, Alternaria alternata, Aspergillus niger, A. fumigatus, A. flavus, Fusarium oxysporum, Penicillium sp, Rhizopus stolonifer, Saccharomyces cerevisiae. The occurrence $\%$ of A. alternata and A. niger was the highest (60\% and $58 \%$ respectively). The n-hexan extract of date seeds(DSE) were prepared for two extraction periods(15 and 20 hours), they were tested externally to reduced the rate of rotten fruit, to test their anifungal activity against $A$. alternata (invitro), and to copare with mint and thyme oils. Results showed that DSE reduced the rate of rotted fruits to $30 \%$. It also showed antifungal activity against $A$. alternata in both invitro and invivo tests. The comparison test showed that DSE less activity than oil of mint had highest thn oil of thyme.

Keywords: Tomato; Date Seeds Extract; N-Hexane; Shelf Life; Antifungal; Alternaria

\section{Introduction}

The plant/Tomato Solanum lycopersicum Mill (Solanaceae) is one of the most popular and widely grown crops in the world. Its yearly global production reaches 160 million tons [1]. Because of their high-water content and other physiological characteristics [2], tomatoes are one of the most perishable vegetable crops. Tomatoes spoilage resulte from pre-harvest as well as post-harvest factors such as field temperature and humidity followed by poor handeling during harvesting, transporting, and storage. Such effects are markedly increase the instances of microbial rot

[3].

\section{Treatment of Tomato Crop by Plant Oils}

There are several applications to control and to minimize harms in fresh and soft fruits, including tomatoes. These techniques are necessary and accompany the crops from the field to the consumers. Using essential oil to reduce fruit decay and their vapours attract more attention than chemicals. They are safe for humans to use and affect the environment less than chemechals $[4,5]$. Several noteworthy plant-based oils come from cloves, oregano, rosemary, thyme, sage and 


\section{Open Access Journal of Mycology \& Mycological Sciences}

vanillin are mentioned as effective agents against bacteria which cause tomatoes spoilage, the antibacterial effect of these oils related to phenolic components, he also stated that the vapour from Eucalyptus and Cinnamon oils represented a notable lowering of strawberry and tomato fruits decay [6].

Thyme oil showed activity against Botrytis cinerea, and Alternaria arborescens developed experimentally on tomato fruits. Aspergillus niger, Rhizopus stolonifer, Fusarium oxysporum, Saccharomyces cerevisiae, Alternaria alternata, Penicillium digitatum and Geotrichum candidum are the most common causes of tomatoes harm [7]. Other effective fungi were listed by include Aspergillus phoenicis, Absidia spp, Trichoderma spp, Alternaria alternata, Fusarium oxysporum, F. moniliformis, Aspergillus niger, Mucor spp, Rhizopus stolonifer, Penicillium spp, Geotrichum spp and Phytophthora spp $[8,9]$.

\section{Date Palm Seed Oil}

There are many different uses of date palm seeds, and one of the most important is the therapeutic applications [10]. The extractions of seeds via water or organic solvents showed antibacterial and antifungal activity [11]. The water, methanol, and acetone extracts of pits revealed significant activity against numerous species of Fusarium, Alternaria, and Trichoderma [12].

In the current study the antifungal activity of n-hexan extract of date palm seeds (Phoenix dactylifera) was (invivo \&invitro) tested against Alternaria alternata as the most comon fungal isolet associated with tomato samples.

\section{Materials and Methods}

During December 2018 a thirty sisty fruits of local cultivar of tomato were collected from several markets in Erbil city, they were approximately with the same size. Fruits were kept sigelly in clean, plastic cups, with caps for five days in a lab environment. The developing fungi were identified according to morphological characteristics based on $[13,14]$. A Pure culture of Alternaria alternata was prepared and was kept in the refrigerator for next tests. Occurrence $\%$ of fungal genera was estimated [15].

\section{Preparation of Date Seeds Powder}

The mature date palms (CV Berhee) were purchased from Basrah province market (south of Iraq). Seeds were cored manually from the fleshy fruits; they were cleaned by tap water then were air dried in lab environment for seven days. The dried seeds were carefully grinded by electrical grinding machine (Electrical Power Grinder/DE-1000g). The grinded material has been sifted by manual sieve (pores $=1 \mathrm{~mm}$ ), a closed glass container was used to kept the powder at $4^{\circ} \mathrm{C}$.

\section{Preparation of Date Seed Extract (DSE)}

Twenty five gram of seed powder and $125 \mathrm{ml}$ of n-hexane were used in soxhlet apparatus to get the seed extract. Seed powder was loaded in a thimble of extractor while the solvent was poured into the round flask $(500 \mathrm{ml})$. Hexan was heated to $68^{\circ} \mathrm{C}$, and two periods of extractions were conducted, 20 hours (T1) and 15 hours (T2). At the end of extraction period, the resedual hexan in the round flasc was evaporated by heated waterbath. The final extractions looked as thick brown liquids, and they were kept in a universal screw cap at $4^{\circ} \mathrm{C}$ for further examination.

\section{The Antifungal Activity Tests}

They involved conducting four consecutive tests:

$>$ Primary evaluation of (T1 and T2) DSE effectiveness against fungi associated externally with tomatoes fruits .

$>$ Use the the disc diffusion method as in vitro test to compare between the antifungal activity of (T1 and T2) of DSE against the predominat isolet Alternaria alternata

$>$ Use the expermintally contaminated tometoes to explain the actevity of DSE (T1and T2) aginst Alternaria alternata.

$>$ Comparison the antifugal activity of DSE with oils of mint (Mentha $s p$ ) and thyme (Thymus $s p$ ).

The tests were conducted as following:

- A three groups of (20 fruits) were used for the primary evaluation the antifungal activity of (T1 and T2) DSE. All selected fruits approximately had the same size, colour, and without blemishes nor injuries, they related to the same yield patch. Two drops of DSE were spread on the surface of the fruit, while the untreated group was regarded as a control test. The samples were kept separately in clean plastic covered cups and were checked after 7 days to record the rate of fungal development.

- The in vitro antifungal activity of (T1 and T2) extracts were carried out against $A$. alternata isolate. A disc ( $5 \mathrm{~mm}$ in diameter) of 7 days old of $A$. alternata pure culture was placed on the centre of growth medium surface. Sterilized discs $(6 \mathrm{~mm})$ of filter paper (Whatman no.1) were soaked for two minutes in the DSE, and after removing the excess extraction, the discs were placed around the fungal disc $(2 \mathrm{~cm}$ apart). The plates were done in duplicate and were incubated at $25^{\circ} \mathrm{C}$. The result was adopted when Alternaria growth reached the control disc. Antagonism of T1-DSE has compared again with n-hexan by disc diffusion method using separated culture plates.

- In vivo test for antifungal activity of (T1-DSE). The test was carried out-after modification-according to $[16,17]$. Healthy tomato fruits were externally sterilized by $2 \%$ of sodium hypochlorite (laundry bleach), thereafter 
they were intensively washed by sterilized distilled water then were air-dried inside the laminar airflow. The fruits were experimentally infected by A. alternata spores suspension, a sterile lancets had been used to wound fruits superficially (two crossed lines with $1 \mathrm{~cm}$ length), the wounds were contaminated by a drop of spores suspension, after 30 minutes two drops of DSE was droped on the wonds by sterilized droppers. Fruits without contaminated wounds were conducted as a control test. Mycelial growth on the wound indicates to fungal colonization. The distingwishable conidia of $A$ alternata was recognized again from the contaminated injuries a. Six fruits were used for each test.

- The antifungal activity of DSE was compared with mint and thyme oils which were purchased from privet plants pharmacy in Erbil city. Disc diffusion method, as well as in vivo test (using experimentally infected eruits ) were followed as mentioned above in [4].

\section{Results and Discussion}

Extending the shelf life of tomatoes was a goal of several previous works. Different environmentally friendly applications were used to control physiological and mechanical changes [18-20]. In contrast, less attention is given to use these phytochemicals as an antifungal for extending tomatoes shelf life. The presumption is that current study is a sign to use DSE in this subject. A local tomato cultivar was chosen in the current study due to its short shelf life, and is prone to damage, compared to imported cultivars. The local tomatoes fruit are lobed, juicy and soft with thin cuticle coat that makes it easier to get injuries (Figure 1).

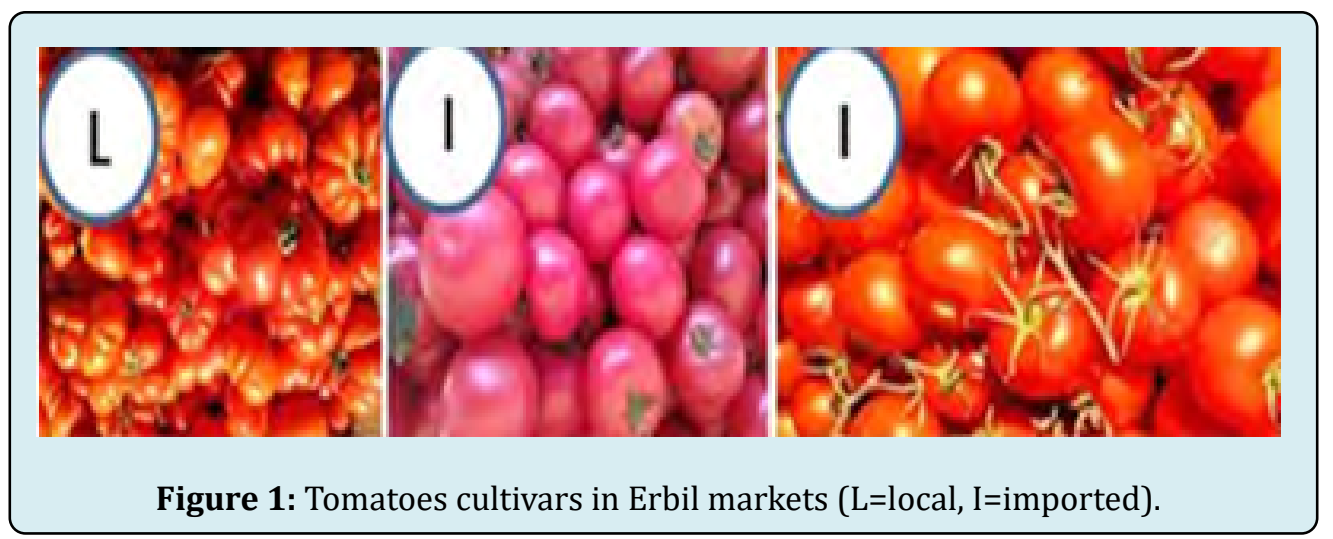

Nine isolates related to seven fungal genera were identified from tested tomaoes, Absidia corymbifera, Alternaria alternata, Aspergillus niger, A.fumigatus, A. flavus, Fusarium oxysporum, Penicillium sp, Rhizopus stolonifer, Saccharomyces cerevisiae. They were comonly causes of tomatom spoilag [21]. Alternaria alternata and Aspergillus niger had the highest occurrence \% (Table 1). Alternaria is one of the most common fungi that cause tomatoes postharvest disease in Iraq Firas, et al. [22], so it was selected as a target for study.

\begin{tabular}{|c|c|c|}
\hline & Fungi & $\mathbf{0 \%}$ \\
\hline 1 & Alternaria alternata & $60 \%$ \\
\hline 2 & Aspergillus niger & $58 \%$ \\
\hline 3 & Penicillium sp. & $33 \%$ \\
\hline 4 & Fusarium oxysporum & $23 \%$ \\
\hline 5 & Rhizopus stolonifer & $16 \%$ \\
\hline 6 & A.fumigatus & $6 \%$ \\
\hline 7 & Saccharomyces serevisiae & $4 \%$ \\
\hline 8 & Absidia stolonifer & $2 \%$ \\
\hline 9 & A. flavuss & $2 \%$ \\
\hline
\end{tabular}

Table1: The occurrence\% (0\%) of isolated fungi.

All untreated fruits exhibit fungal growth(damage $=100 \%$ ). Date seeds extract reduced the rate of damaged fruits to (30\%) as well as minimize fungal growth. T1-DSE reduced fungal growth more than T2-DSE (Figure 2). 

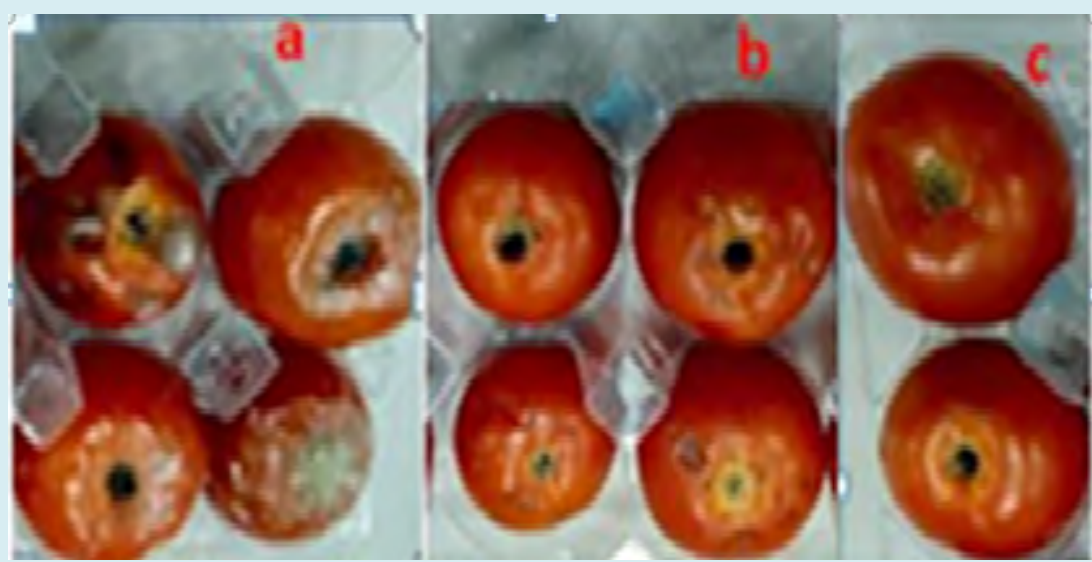

Figure 2: A: untreated fruits, B: fruits treated by T2- DSE, C: fruits treated by T1-DSE.

Date seeds extract had several phytochemicals such as flavonoids, anthocyanidins, and glycosides, which act as fungal growth inhibitors [23,24]. The different effectiveness between $\mathrm{T} 1$ and $\mathrm{T} 2$ related to the difference in their compenets ratios. Several studies reported that the extraction time effect on the ingredients retios besides the type of solvent, and particles size [25]. In vitro comparison between the activity of T1-DSE and T2-DSE against Alternaria alternata was recorded when the fungal growth reached the edge of the control disc(n-hexane). The test showed that the inhibition zone of T1-DSW was $4 \mathrm{~mm}$ while it was $2 \mathrm{~mm}$ for T2-DSE. (Figure 3-A). The activity of T1-DSE was confirmed and was compare by separating culture plates (Figure 3-B \& C), the range of clear zone was $8-20 \mathrm{~mm}$ for T1-DSE (Figure 3 -B), while there is no effect for $n$-hexan as control (Figure $3-C)$.

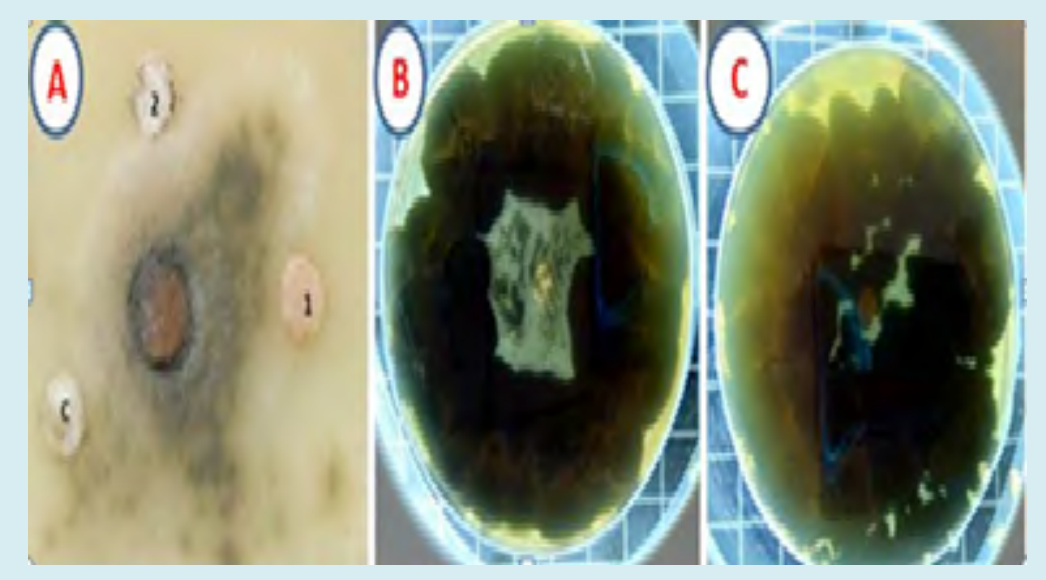

Figure 3: A: Discs diffusion method: 1=T1, 2=T2, 3=n-hexane, B: $\mathrm{T} 1$ disc in the centre, C: $\mathrm{n}$-Hexane disc in the centre.

The effectiveness of T1 DSE on experimentally infected fruits showed that $A$. alternata failed to colonize the treated fruits (inhibition=100\%), while fungal growth was observed on $91.6 \%$ of untreated tometoes of which $81.8 \%$ was Alternaria. This means that activity of DSE was not affeceted by plant tissue environments. The antifungal activity of DSE was compared with that of mint and thyme oils which have a distinguished effecacy against several fungi [26-28]. Oil of mint showed the largrst zone of inhibition followed by DSE and thyme oil (6mm, 4mm, 1-2mm respectively) (Figure 4). 


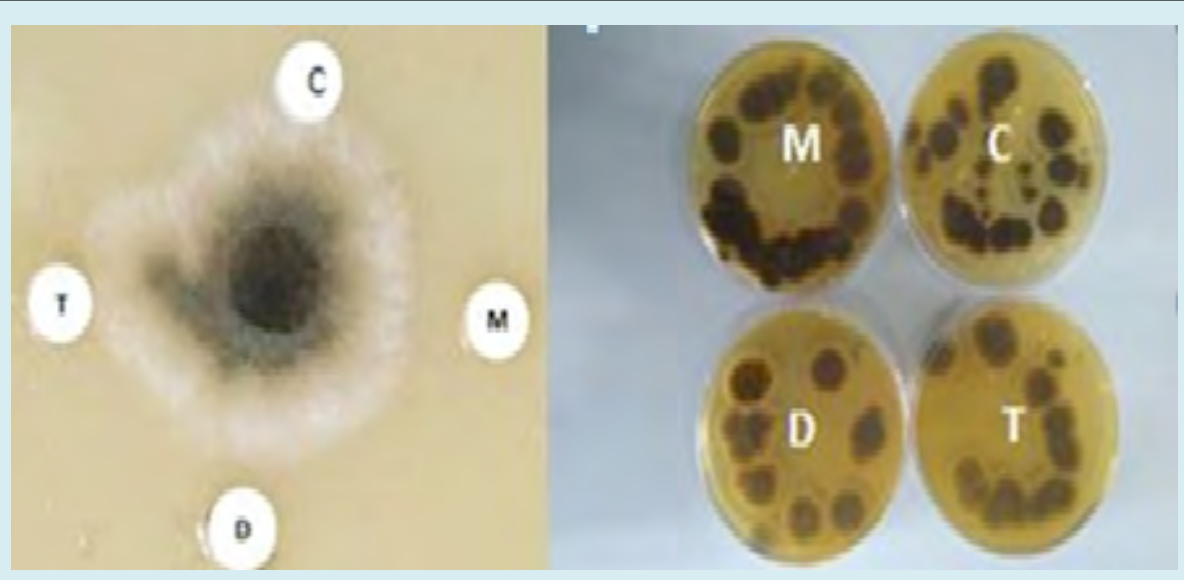

Figure 4: Disc diffusion test of (mint oil=M), (DSE=D), (thyme oil=T) and (n-hexane=C) against A.alternata.

The comparison test by expermantaly infected tomatoes(invitro) showed the same results.Mint oil caused an absolute disappearance of Alternaria growth on infected fruits (inhibition=100\%). (Figure 5-M). Thyme oil (Figure 5-T) showed low antifungal activity rate (33\% inhibition) in compare with DSE (66\%) (Figure 5-D).

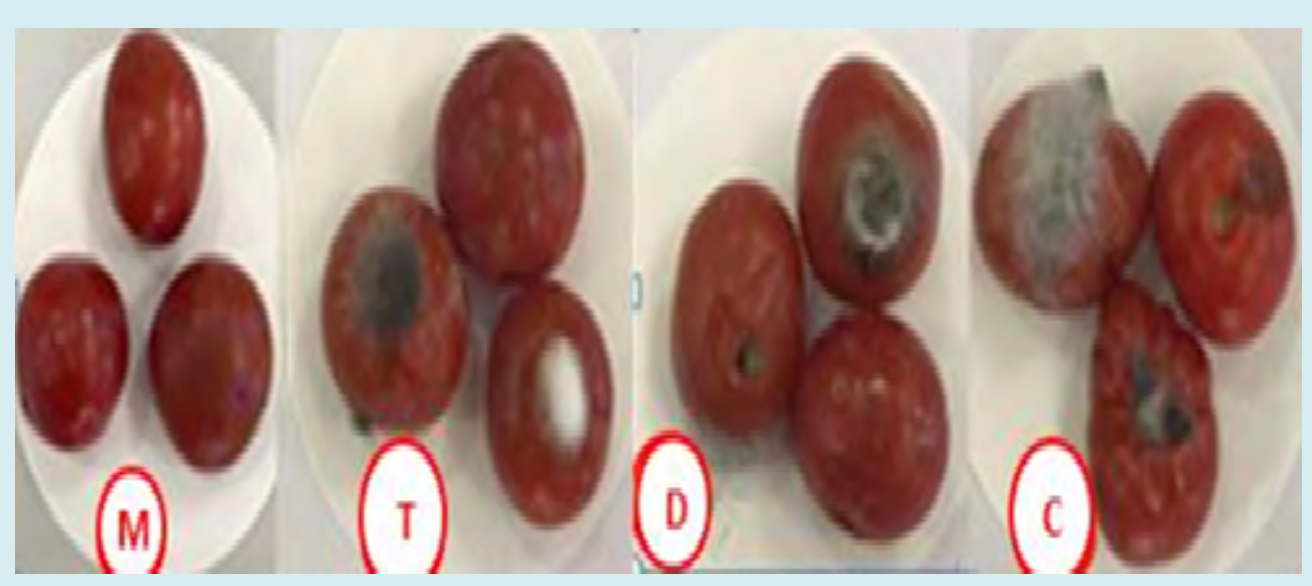

Figure 5: Antifungal activity of (mint oil=M), (thyme oil=T), (DSE=D), and (n-hexane=C) against A.alternata in artificially infected fruits.

\section{Conclusion}

According to the results of current study, the n-hexan extract of date seeds has ihibitory action against fungal contamination of tomatoes. It may use to prevent tomato spoilage successfully and extending their shelflife. Further studies should be conducted for several safety applications of date seeds extract as a natural antifungal agent.

\section{References}

1. Pathak TB, Stoddard SC (2018) Climate change effects on the processing tomato growing season in California using growing degree day model. Modelling Earth Systems and Environment 4(2): 765-775.

2. Abdul Hammed M, Bello IA (2009) Comparison of biochemical and physiological properties of Nigerian tomato fruits ripened under different conditions. Africana Journal of Food, Agriculture, and Nutritional Development 9(9): 1858-1877.

3. Elda B, Rosam R (2018) Post-harvest management of tomato for quality and safety assurance. Guidance for horticultural supply chain stakeholders. Food and agriculture organization of the United Nations Rome, pp: 


\section{Open Access Journal of Mycology \& Mycological Sciences}

$1-17$.

4. Kojo IA, Gerald K, Anku AE, Kumah EK, Amaglo H (2016) Postharvest Handling practices and treatment methods for tomato handlers in developing countries: A Mini Review. Advances in Agriculture, pp: 8.

5. Marino M, Ramos HC, Hoffmann T, Glaser P, Jahn D (2001) Modulation of anaerobic energy metabolism of Bacillus subtilis by arfM (ywiD). J Bacteriol 183(23): 6815-6821.

6. Tzortzakis NG (2007) Maintaining postharvest quality of fresh produce with volatile compounds. Innovative Food Scicence and Emerging Technologies 8(1): 111-116.

7. Ghosh A (2009) Identification of microorganisms responsible for spoilage of tomato (Lycopersicum esculentum) fruit. Journal of Phytology 1(6): 414-416.

8. Akinmusire 00 (2011) Fungi species associated with the spoilage of some edible fruits in Maiduguri North eastern Nigeria. Advances in Environmental Biology 5(1): 157-161.

9. Wani HA (2011) An overview of the fungal rot of tomato. Mycopath 9(1): 33-38.

10. Niazi S, Mahmood IK, Imran Pasha, Rashee S, Ahmad S, et al. (2017) Date Palm: Composition, health claim and food applications. International Journal of Public Health and Health Systems 2(1): 9-17.

11. Bentrad N, Gaceb Terrak R (2017) Studies on Chemical Composition and Antimicrobial activities of bioactive molecules from date palm (Phoenix dactyliferal L.) Pollens and seeds. Afr J Tradit, Complement Altern Med 14(3): 242-256.

12. Abushaala FA, Ben Ramadan AR, Fahej MAS (2017) In vitro antifungal activity of some plant extracts against seed-borne pathogens. IOSR Journal of Agriculture and Veterinary Science 10(4): 49-57.

13. Seifert KA (2007) Compendium of Soil Fungi. In: Domsch $\mathrm{KH}$, Gams W, et al. (Eds.), European Journal of Soil Science 59(5): 1007.

14. Woudenberg JH, Groenewald JZ, Binder M, Crous PW (2013) Alternaria redefined. Stud Mycol 75(1): 171- 212.

15. Al Bader SM, Ismael LQ, Ahmood AA (2018) Fungal contamination of air conditioner units in five hospitals of Erbil province-Kurdistan region/Iraq. SJUOZ 6(4): 146-149.

16. Basurto ED, Isabel $M$, Sanchez Estrada A, Tiznado Hernandez EM, Félix AR, et al. (2017) Alteration in volatile metabolites profile of fresh tomato in response to Alternaria alternata (Fr.) Keissl. 1912 infection. Chilean journal of agricultural research 77(3).

17. El Katatny M, Emam A (2012) Control of postharvest tomato rot by spore suspension and antifungal metabolites of Trichoderma harzianum. J Microbiology Biotechnology and Food Sciences 1(6): 1505-1528.

18. Ahmed L, Martin Diana A, Rico D, Barry Ryan C (2012) Extending the shelf-Life of tomato using by product from cheese industry. Dublin Institute of Technology, School of food science and environment health 36: 141-151.

19. Nurudeen O, Adetayo O (2014) Shelf-life extension of tomato (Lycopersicum esculentum) and pepper (Capsicum annuum) using aqueous extracts of some ethno medicinal plants. Journal of Agricultural Science and Technology 4: 806-810.

20. Ibrahim FAA, Al Ebady N (2014) Evaluation of antifungal activity of some plant extracts and their applicability in extending the shelf life of stored tomato fruits. Journal of food processing and technology.

21. Samuel 0, Orji MU (2015) Fungi associated with the spoilage of post-harvest tomato fruits sold in major markets in Awka, Nigeria. Universal Journal of Microbiology Research 3(2): 11-16.

22. Firas AA, Sipes BS, Anne MA (2017) Posthrves diseases of tomato and natural products for disease management. African Journal of Agricultural Research 12(9): 684-691.

23. Yassein NN (2012) Antibacterial effect of date palm (Phoenix dactylifera L.) pit aqueous extract on some bacteria cause urinary tract infection. Diyala journal of pure science 8(3): 112-120.

24. Kumar S, Pandey AK (2013) chemistry and biological activities of flavonoids: an overview. Scientific World Journal, pp: 16.

25. Al Sumri A, Al Siyabi N, Al Saadi R, Al Rasbi S, Al Dalla A (2016) Study on the extraction of date palm seed oil using soxhlet apparatus. International Journal of Scientific \& Engineering Research 7(12): 1266-1270.

26. Ragab MMM, Ashour AMA, Abdel Kader MM, El Mougy NS, Abdel Aziz A (2016) Fungicidal and Fungistatic Activity of some plant Essential oils against Alternaria solani the causal of tomato early blight. Research Journal of Pharmaceutical, Biological and Chemical Sciences 7(4): 998.

27. Mironescu M, Georgescu C (2008) Preliminary researches on the effect of essential oils on moulds isolated from 


\section{Open Access Journal of Mycology \& Mycological Sciences}

surfaces. Journal of Agroalimentary Processes and Technologies 14(30): 33.

28. Plotto A, Roberts RG, Roberts DD (2003) Evaluation of plant essential oils as natural postharvest disease control of tomato (Lycopersicum esculentum). Acta Horticulturae 628: 737-745. 